\title{
Failure Rate of Direct High-Viscosity Glass-Ionomer Versus Hybrid Resin Composite Restorations in Posterior Permanent Teeth - a Systematic Review
}

\author{
Steffen Mickenautsch ${ }^{*}$ and Veerasamy Yengopal
}

\begin{abstract}
SYSTEM Initiative/Department of Community Dentistry, Faculty of Health Sciences, University of the Witwatersrand 7 York Rd., Parktown/Johannesburg 2193, South Africa
\end{abstract}

\begin{abstract}
:
Purpose

Traditionally, resin composite restorations are claimed by reviews of the dental literature as being superior to glassionomer fillings in terms of restoration failures in posterior permanent teeth. The aim of this systematic review is to answer the clinical question, whether conventional high-viscosity glass-ionomer restorations, in patients with single and/or multi-surface cavities in posterior permanent teeth, have indeed a higher failure rate than direct hybrid resin composite restorations.
\end{abstract}

\begin{abstract}
Methods
Eight databases were searched until December 02, 2013. Trials were assessed for bias risks, in-between datasets heterogeneity and statistical sample size power. Effects sizes were computed and statistically compared. A total of 55 citations were identified through systematic literature search. From these, 46 were excluded. No trials related to highviscosity glass-ionomers versus resin composite restorations for direct head-to-head comparison were found. Three trials related to high-viscosity glass-ionomers versus amalgam and three trials related to resin composite versus amalgam restorations could be included for adjusted indirect comparison, only.
\end{abstract}

\section{Results}

The available evidence suggests no difference in the failure rates between both types of restoration beyond the play of chance, is limited by lack of head-to-head comparisons and an insufficient number of trials, as well as by high bias and in-between-dataset heterogeneity risk. The current clinical evidence needs to be regarded as too poor in order to justify superiority claims regarding the failure rates of both restoration types. Sufficiently large-sized, parallel-group, randomised control trials with high internal validity are needed, in order to justify any clinically meaningful judgment to this topic.

Keywords: Failure rate, high-viscosity glass-ionomers, posterior permanent teeth, resin composite, systematic review, tooth restorations.

\section{INTRODUCTION}

In recent years, the use of resin composites for the placement of posterior permanent tooth restorations has increased, particularly because of its better esthetic properties and the general concerns about the limitations of amalgam [1,2]. Notwithstanding, a systematic review by Antony et al. (2008) concluded that composite resin

\footnotetext{
* Address correspondence to this author at SYSTEM Initiative/ Department of Community Dentistry, Faculty of Health Sciences, University of the Witwatersrand, 7 York Rd., Parktown/ Johannesburg, 2193, South Africa; Tel No. +27 11717 2594; Fax No. +27 11717 2625; E-mail: neem@global.co.za
}

fillings show a shorter longevity than amalgam fillings [3].

In contrast to resin composite, conventional glassionomer cements (C-GIC), defined as chemically curing materials without a resin component, have traditionally been considered as inferior restorative materials [4 - 7]. Downer et al. (1999) [4], Hickel et al. (2000) [5], Hickel and Manhart (2001) [6] and Manhart et al. (2004) [7] have published influential and highly cited reviews of the dental literature with relevance to the longevity of various restorative materials, including C-GIC. The findings of these reviews, based on mainly uncontrolled longitudinal studies and laboratory investigations, 
conclude that C-GICs are less durable, with a far higher failure rate, than resin composite when placed as posterior occlusal or approximal restorations [4 - 7]. For these reasons $\mathrm{C}$-GIC were regarded as lacking adequate mechanical properties for general use as definitive restorations in stress-bearing posterior teeth.

Over the last twenty years, the term 'high-viscosity' or 'high-viscous' C-GICs (HVGIC) has emerged within the scientific dental literature. HVGICs appear distinct from other (low) viscosity C-GICs (including metalreinforced C-GICs/Cermets) in comparison of their survival rate to that of conventional amalgam restorations. The results of a meta-analysis by Frencken et al. (2004) found a survival rate for HVGIC (Fuji IX; Ketac Molar) similar to that of amalgam but showed significantly lower survival rates for "low-viscosity" GICs (Chelon Silver/Cermet; Chem Fil; Fuji II) than for amalgam [8]. Subsequent systematic review evidence from clinical randomised control trials (RCTs) has confirmed the earlier meta-analysis results [9, 10]. In particular for direct HVGIC restorations placed in the permanent dentition, the clinical evidence shows: (i) no difference between single-surface HVGIC and conventional amalgam restorations in their failure rates after six years; (ii) no difference in the failure rates of multiple-surface HVGIC and conventional amalgam restorations after four years [9, 10].

Despite many published reviews of the dental literature [4 - 7], no systematic review evidence based on the comparative effect estimates concerning the clinical failure rate of direct tooth restorations placed in posterior permanent teeth using HVGIC, with resin composite as control intervention, is available. Therefore, the aim of this systematic review was to answer the question as to whether conventional high-viscosity glass-ionomer restorations, in patients with single and/or multi-surface cavities in posterior permanent teeth, have indeed a higher failure rate than direct hybrid resin composite restorations.

\section{MATERIALS AND METHODOLOGY}

The protocol of this systematic review has been registered with the International Prospective Register of Systematic Reviews (PROSPERO / Nr: CRD42013006487) and was published in an open access journal [11].

\section{Systematic Literature Search}

Electronic international databases: PubMed/Medline and CENTRAL (Cochrane Library); databases of open access journals: Directory of Open Access Journals (DOAJ) and Biomed Central; regional databases:
IndMed and Sabinet, as well as databases for greyliterature: OpenSIGLE and GoogleScholar were searched by both authors independently. The details of the search strategies, including the strings of search terms (containing MeSH and text search terms) together with Boolean operators, per databases are presented in Additional file S1/Section 1. All databases were searched until 02.12.2013, the cut-off date. Citations were eligible for possible inclusion if in line with the following inclusion criteria:

i. Full report of a prospective clinical control trial

ii. Clearly reported parallel group design with dichotomous outcome measure

iii. Outcome measure: restoration failure due to fracture, wear, and secondary caries and/or retention loss

iv. Intervention in load bearing cavities of permanent posterior teeth

v. Follow-up period: 1 year or longer with longest comparable result per study

vi. Trials comparing:

i. Resin composite versus amalgam

ii. HVGIC versus amalgam

iii. HVGIC versus resin composite

Trial participants comprised all patients of any age, gender or place of origin with suitable tooth cavities in posterior permanent teeth.

Articles were further excluded according to the criteria:

i. Tunnel restoration or preventive resin restoration (sealed restoration) as intervention type

ii. Cermet or low-viscosity glass-ionomer cements as test intervention

iii. Chemically curing composite resin or non-hybrid resin composite as control intervention

iv. Low-copper amalgam alloys as control intervention

v. Resin composite and/or amalgam restorations placed with GIC liner or base

vi. No computable data ( $n=$ number of failures; $N=$ total number of evaluated units, per intervention group) reported

vii. Tooth cavities on anterior teeth, Class V cavities or cavities on root/cervical tooth surfaces

viii. Tooth cavities extending into enamel only

ix. For possible network-meta analysis or indirect treatment comparison (ITC), only datasets that matched in regard to restored cavity type and follow-up period, as well as with low statistical heterogeneity (Cochrane's Q-test $/ p>0.10 / I^{2}<$ $45 \%$ ) were included. 
x. Articles that could not be traced in full copy were also excluded.

Two reviewers (SM and VY) scanned titles and abstracts of identified citations from data sources in duplication. Articles with suitable titles but lacking listed abstracts were retrieved in full copy. All included articles were judged separately by the authors: for possible exclusion, with reason, or for acceptance, in line with the exclusion criteria. Disagreements between authors were resolved through discussion and consensus.

\section{Assessment of Internal Validity/Bias Risk}

Verbatim quotes relevant to selection-, performanceand detection bias risk were extracted from all accepted trial reports. Assessment of the risk of selection bias and detection/performance bias was based on these, using criteria [12], shown in Additional file S1/Section 2.

In order to assess attrition bias risk, worst- and bestcase scenarios were assumed. These were calculated in cases were the number of lost trial participants per intervention group was reported in the trial reports. The results were then compared to the intervention outcomes computed for participants available to follow-up. On this basis conclusions concerning attrition bias risk were drawn: high risk of attrition bias was assumed if the computed outcomes between worst- and best-case scenario and the intervention outcomes computed for participants available to follow-up differed significantly. Where the number of lost trial participants per intervention group was not reported, a high risk of attrition bias was assumed by default.

The worst-case scenario was calculated by adding the number of lost-to-follow-up participants in the test group to the failures of that group and adding the number of lost-to-follow-up participants in the control group to the successes of that group. The best-case scenario was calculated by adding the number of lost-to-follow-up participants in the test group to the successes of that group and adding the number of lost-to-follow-up participants in the control group to the failures of that group. Intervention outcomes were computed for assessment of attrition bias as Relative risks (RR) with 95\% Confidence intervals (CI). The two reviewers conducted the assessment separately. Disagreements were resolved through discussion and consensus.

In order to assess the risk of publication bias, the following trial registers and electronic sources were searched for abstracts and/or titles of trials in line with trial selection criteria as per sections: Australian New Zealand Clinical Trials Registry; Clinical Trials US; EU Clinical Trials Register; metaRegister of Controlled Trials ( $m$ RCT); South African National Clinical Trials
Register; WHO Clinical Trials; IADR abstracts; International Poster Journal of Dentistry and Oral Medicine. Comparison of the number of identified unpublished with the number of published (accepted) trials was used to assess the possible extent of potential publication bias risk.

Graphical and statistical assessments of publication bias risk were planned if the number of extracted datasets exceeded ten.

\section{Data Extraction and Statistical Analysis}

Acceptable outcome measures were the number of restoration failures $(n)$ from the total number of evaluated units $(N)$ for dichotomous data. Restoration failures were defined as: fractured restorations; secondary caries on restoration margins; partial or total loss of restoration retention; excessive wear of the restoration material. Only primary outcomes with either the patient or the tooth as unit of analysis were accepted. For each extracted dataset of $n / N$ for the test- and control groups, the Odds ratio (OR) with 95\% Confidence intervals (CI) and significance levels ( $p$ values) were computed, using the statistical software programme Rev Man 4.2. The 5\% significance level was used. In addition, each accepted dataset was assessed as to whether it contained the minimum sample size needed in order to have $>80 \%$ power for detecting an effect size difference of $10 \%$ between directly compared interventions. (Additional file S2/Section 6). The effect size difference was chosen in keeping with past considerations for sample size calculation [13].

Both authors extracted data from accepted trials independently, without being blinded to authors, institutions, journal names and trial results. Disagreements between authors concerning extracted data were solved through discussion and consensus. All extracted data were entered in specifically designed MS Excel data sheets.

\section{Assessment and Investigation of In-Between-Dataset Heterogeneity}

To fulfill the criteria of clinical and methodological homogeneity, datasets from trials should not have differed with regard to the following minimum set of characteristics: outcome measure; control intervention; cavity type restored; assessment method and length of follow-up period. If in-between-dataset differences were identified, heterogeneity was assumed and the datasets were excluded from analysis.

The $I^{2}$ - test with $95 \%$ CI, as well as Cochrane's Qtest, was used to determine whether any statistical heterogeneity might exist between datasets. Thresholds 
for $I^{2}$ point estimates (in \%) and their upper confidence values were used in order to interpret the test results: $0-40 \%=$ might not be important; $30-60 \%=$ may represent moderate heterogeneity; $50-90 \%=$ may represent substantial heterogeneity; $75-100 \%=$ considerable heterogeneity [14].

Across different trials, only datasets that showed lack of statistical in-between heterogeneity were considered eligible for indirect comparison. The cut-off point for statistical heterogeneity was set at $I^{2}>40 \%$ and Cochrane's Q-test $/ p$-value $<0.10$. However, datasets in compliance with these set test criteria were not assumed to be free of in-between heterogeneity, particularly due to the weak statistical power of both tests when the number of datasets are low [15], but were further investigated in the form of trial characteristics comparison tables.

\section{Types of Comparisons Between Test- and Control Groups}

\section{Direct Comparisons}

Direct comparisons were considered to be comparisons between intervention groups within a controlled clinical trial setting [16]. The systematic literature search of this review aimed to identify clinical trials that directly compared HVGIC with resin composite restorations, in line with the stated inclusion/exclusion criteria.

\section{Adjusted Indirect Comparisons}

It has been reported that only a few clinical trials that have directly compared HVGIC with resin composite restorations have yet been conducted [17]. As it was possible that any existing clinical trials may not have complied with the stated inclusion/exclusion criteria of this review, the use of adjusted indirect comparison was considered. Adjusted indirect comparison between intervention groups may preserve the strength of an $\mathrm{RCT}$, if adjusted according to the results of their direct comparison with a common control [18]. Therefore, the systematic literature search was extended to identification of clinical trials that: (i) compare HVGIC with amalgam restorations and (ii) compare resin composite with amalgam restorations. Consequently, this systematic review would also statistically compare the clinical results of HVGIC versus amalgam trials with the clinical results of the resin composite versus amalgam trials through use of Indirect Treatment Comparison (ITC) or, if possible, network meta-analysis [19, 20].

For ITC, the statistical methodology given by Bucher et al. (1997) was applied [21, 22]. The results were confirmed through use of the ITC software developed by the Canadian Agency for Drugs and Technologies in Health (2009) [23]. All indirect comparison results were reported as Odds ratios (OR with 95\% CI).

\section{RESULTS}

\section{Systematic Literature Search and Data Selection}

(Fig. 1) provides information on the number of articles identified. From the generated citations, 55 clinical trials were provisionally included. Of these, three could not be traced in full [24 - 26].

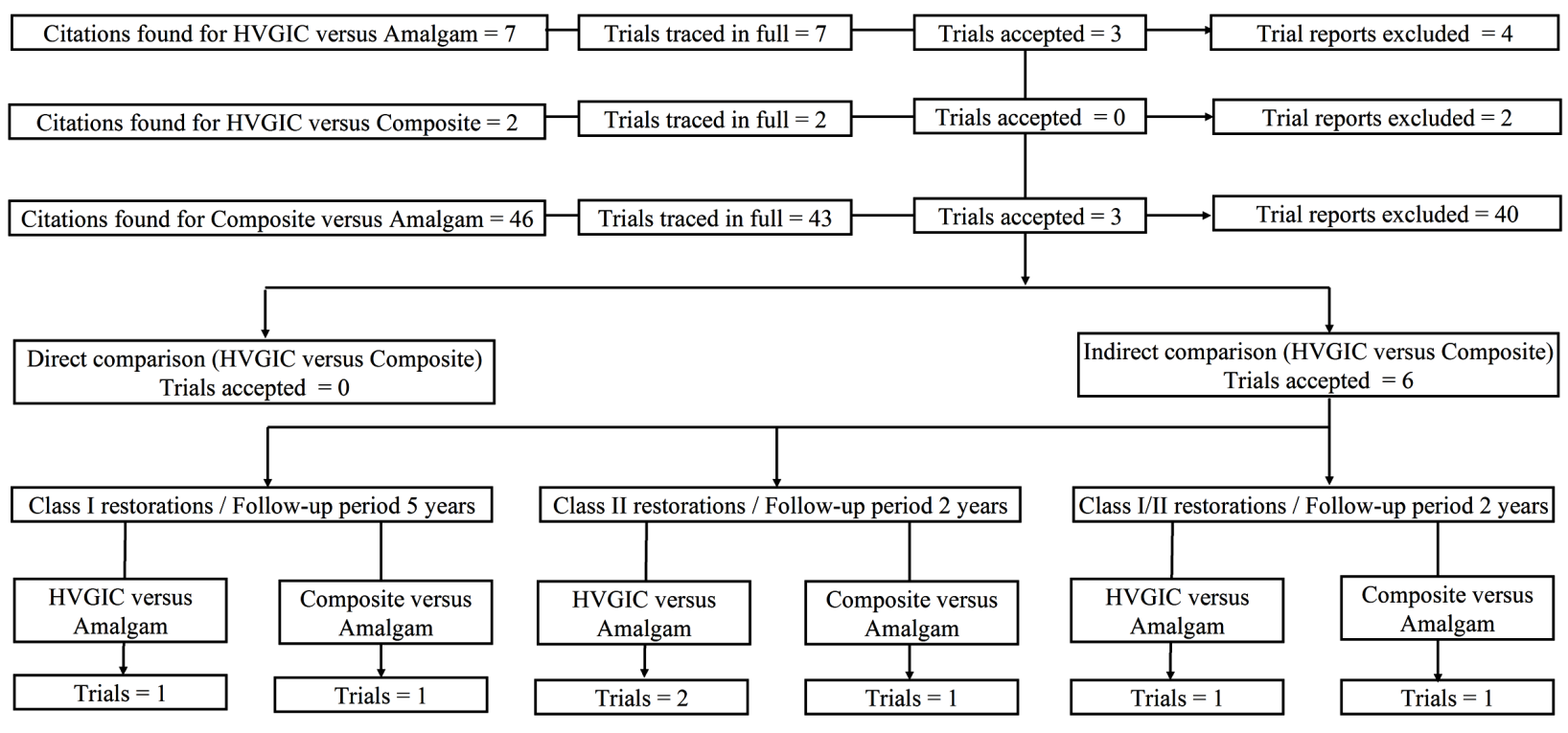

Fig. (1). Flow diagram of trial selection. 
Thus 52 trials were included for further review: 7 trials were related to HVGIC versus amalgam restorations, 2 trials were related to HVGIC versus resin composite restorations and 43 trials were related to composite versus amalgam restorations.

From these trials, a total of 46 were excluded. Reasons for exclusion are listed in Additional file S2/Section 1.

Six trials were accepted for data extraction: three related to HVGIC versus amalgam restorations [27 - 29] and three to resin composite versus amalgam restorations [2, 30, 31]. Details of all accepted trials are presented in Additional file S2/Section 3.

\section{Assessment of Internal Trial Validity/Bias Risk}

Assessment of selection- and performance-/detection bias risk was based on verbatim quotes extracted from all six accepted trials (Additional file S2/Section 5). Details of the assessment results are presented in Table 1.

Table 1. Assessment of selection-, performance- and detection bias risk.

\begin{tabular}{|c|c|c|c|c|c|c|c|}
\hline First author & Journal & Year & Vol. & First page & SB & PB & DB \\
\hline Sachdeo [31] & EurJProsthodontRestDent & 2004 & 12 & 15 & 0 & 0 & 0 \\
\hline Soncini [30] & JADA & 2007 & 138 & 763 & $\mathrm{C}$ & 0 & $\mathrm{C}$ \\
\hline Bernado [2] & JADA & 2007 & 138 & 775 & 0 & 0 & 0 \\
\hline Li [27] & PractClinMed & 2005 & 6 & 105 & 0 & 0 & 0 \\
\hline Frencken [28] & JDR & 2006 & 85 & 622 & 0 & 0 & $\mathrm{C}$ \\
\hline Estupiñán-Day [29] & PAHO-report/Ecuador & 2006 & & & $\mathrm{C}$ & 0 & 0 \\
\hline
\end{tabular}

$\mathrm{SB}=$ Selection bias; $\mathrm{PB}=$ Performance bias; DB = Detection bias; Vol. = Journal volume; EurJProsthodontRestDent = European Journal of Prosthodontic Dentistry; JADA = Journal of the American Dental Association; PractClinMed = Practice Clinical Medicine; JDR = Journal of Dental Research; PAHO = Pan-American Health Organisation.

The risk of selection- and performance-/detection bias was judged to be high for all trials. Only two trials reported adequate methods of random sequence generation and concealment of the random sequence in order to prevent direct observation (selection bias risk) $[29,30]$. None of the trials reported adequate methods of patient and clinical operator masking as to the type of treatment rendered (performance bias risk) and only two trials [28, 30] reported adequate methods for masking evaluators during the trial assessment period (detection bias risk).

Only datasets that were judged sufficiently homogeneous in line with the trial inclusion criteria were quantitatively assessed for attrition bias risk. The results are presented in Table $\mathbf{2}$ and indicate high bias risk for all except two datasets (CA01 and CA04) from two accepted trials [2, 31].

Table 2. Assessment of attrition bias risk.

\begin{tabular}{|c|c|c|c|c|c|c|c|c|c|c|c|c|c|c|c|c|c|c|}
\hline \multirow{4}{*}{ First author } & \multirow{4}{*}{ Journal } & \multirow{4}{*}{ Year } & \multirow{4}{*}{ Vol. } & \multicolumn{15}{|c|}{ Worst-case scenario } \\
\hline & & & & \multirow{3}{*}{$\begin{array}{l}\text { First } \\
\text { page }\end{array}$} & \multirow{3}{*}{ DS } & \multicolumn{3}{|c|}{ Test group } & \multicolumn{3}{|c|}{ Amalgam group } & \multirow{2}{*}{\multicolumn{3}{|c|}{$\begin{array}{c}\text { LTF adjusted effect } \\
\text { estimate }\end{array}$}} & \multirow{2}{*}{\multicolumn{3}{|c|}{$\begin{array}{l}\text { Original effect } \\
\text { estimate }\end{array}$}} & \multirow{3}{*}{$\begin{array}{l}\text { Bias } \\
\text { risk }\end{array}$} \\
\hline & & & & & & \multirow[b]{2}{*}{ LTF } & \multirow{2}{*}{$\begin{array}{l}N= \\
\text { BSL } \\
\text { teeth }\end{array}$} & \multirow[b]{2}{*}{ n+LTF } & \multirow[b]{2}{*}{ LTF } & \multirow[b]{2}{*}{$\mathbf{N}+\mathbf{L T}$} & \multirow[b]{2}{*}{$\mathbf{n}$} & & & & & & & \\
\hline & & & & & & & & & & & & $\mathbf{R R}$ & $\begin{array}{c}95 \% \\
\text { CI }\end{array}$ & p & $\mathbf{R R}$ & $\begin{array}{c}95 \% \\
\text { CI }\end{array}$ & $\mathbf{p}$ & \\
\hline Sachdeo [31] & EurJProsthodontRestDent & 2004 & 12 & 15 & CA01 & & & & & & & & & no LTF ap & oparen & nt duri & ing trial & No \\
\hline Soncini [30] & JADA & 2007 & 138 & 763 & $\mathrm{CA} 02$ & & & & & & & & & & & & nil & Yes \\
\hline Bernado [2] & JADA & 2007 & 138 & 775 & CA04 & & & & & & & & & no LTF ap & oparen & nt duri & ing trial & No \\
\hline $\operatorname{Li}[27]$ & PractClinMed & 2005 & 6 & 105 & GA02 & & & & & & & & & & & & nil & Yes \\
\hline \multirow{2}{*}{ Frencken $[28]$} & \multirow{2}{*}{ JDR } & \multirow{2}{*}{2006} & \multirow{2}{*}{85} & \multirow{2}{*}{622} & GA07 & 18 & 52 & 21 & 10 & 33 & 10 & 1.33 & $\begin{array}{c}0.72 \\
- \\
2.46\end{array}$ & 0.36 & 0.20 & \begin{tabular}{|c|}
0.06 \\
- \\
0.66
\end{tabular} & $0.008 *$ & Yes \\
\hline & & & & & GA10 & 127 & 288 & 135 & 105 & 218 & 5 & 20.44 & \begin{tabular}{|c|}
8.52 \\
- \\
49.03 \\
\end{tabular} & $<0.00001 * *$ & 1.12 & \begin{tabular}{|c|}
0.38 \\
- \\
3.34 \\
\end{tabular} & 0.83 & Yes \\
\hline $\begin{array}{c}\text { Estupiñán-Day } \\
{[29]}\end{array}$ & PAHO-report/Panama & 2006 & & & GA17 & 144 & 769 & 166 & 118 & 677 & 8 & 18.27 & $\begin{array}{c}9.03 \\
- \\
36.86\end{array}$ & $<0.00001 * *$ & 2.46 & \begin{tabular}{|c|}
1.10 \\
- \\
5.48 \\
\end{tabular} & $0.03 * *$ & No \\
\hline
\end{tabular}




\begin{tabular}{|c|c|c|c|c|c|c|c|c|c|c|c|c|c|c|c|c|c|c|}
\hline \multirow{4}{*}{ First author } & \multirow{4}{*}{ Journal } & \multirow{4}{*}{ Year } & \multirow{4}{*}{ Vol. } & \multicolumn{15}{|c|}{ Worst-case scenario } \\
\hline & & & & \multirow{3}{*}{ First } & \multirow{3}{*}{ DS } & \multicolumn{3}{|c|}{ Test group } & \multicolumn{3}{|c|}{ Amalgam group } & \multirow{2}{*}{\multicolumn{3}{|c|}{$\begin{array}{c}\text { LTF adjusted effect } \\
\text { estimate }\end{array}$}} & \multirow{2}{*}{\multicolumn{3}{|c|}{$\begin{array}{c}\text { Original effect } \\
\text { estimate }\end{array}$}} & \multirow{3}{*}{$\begin{array}{l}\text { Bias } \\
\text { risk }\end{array}$} \\
\hline & & & & & & \multirow[b]{2}{*}{ LTF } & \multirow{2}{*}{$\begin{array}{l}\mathbf{N}= \\
\text { BSL } \\
\text { teeth }\end{array}$} & \multirow[b]{2}{*}{ n+LTF } & \multirow[b]{2}{*}{ LTF } & \multirow[b]{2}{*}{$\mathbf{N}+\mathbf{L T}$} & \multirow[b]{2}{*}{$\mathbf{n}$} & & & & & & & \\
\hline & & & & & & & & & & & & $\mathbf{R R}$ & $\begin{array}{c}95 \% \\
\text { CI }\end{array}$ & $\mathbf{p}$ & $\mathbf{R R}$ & $\begin{array}{c}95 \% \\
\text { CI }\end{array}$ & $\mathbf{p}$ & \\
\hline \multirow{3}{*}{ First author } & \multirow{3}{*}{ Journal } & \multirow{3}{*}{ Year } & \multirow{3}{*}{ Vol } & \multicolumn{15}{|c|}{ Best-case scenario } \\
\hline & & & & \multirow[t]{2}{*}{$\begin{array}{l}\text { First } \\
\text { page }\end{array}$} & \multirow[b]{2}{*}{ DS } & \multicolumn{3}{|c|}{ Test group } & \multicolumn{3}{|c|}{ Amalgam group } & \multicolumn{3}{|c|}{$\begin{array}{c}\text { LTF adjusted effect } \\
\text { estimate }\end{array}$} & \multicolumn{3}{|c|}{$\begin{array}{l}\text { Original effect } \\
\text { estimate }\end{array}$} & \multirow{2}{*}{$\begin{array}{l}\text { Bias } \\
\text { risk }\end{array}$} \\
\hline & & & & & & LTF & $\begin{array}{c}\mathrm{N}+\mathrm{LTF} \\
\text { teeth }\end{array}$ & $\mathrm{n}$ & LTF & $\begin{array}{l}\mathrm{N}= \\
\mathrm{BSL}\end{array}$ & $n+\mathrm{LTF}$ & $\mathrm{RR}$ & $\begin{array}{c}95 \% \\
\mathrm{CI}\end{array}$ & 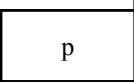 & $\mathrm{RR}$ & $\begin{array}{c}95 \% \\
\mathrm{CI} \\
\end{array}$ & $\mathrm{p}$ & \\
\hline Sachdeo [31] & EurJProsthodontRestDent & 2004 & 12 & 15 & CA01 & \multicolumn{12}{|c|}{ no LTF apparent during trial } & No \\
\hline Soncini [30] & JADA & 2007 & 138 & 763 & CA02 & & & & & & & & & & & & nil & Yes \\
\hline Bernado [2] & JADA & 2007 & 138 & 775 & CA04 & & & & & & & & & no LTF ap & pparer & nt duri & ing trial & No \\
\hline $\operatorname{Li}[27]$ & PractClinMed & 2005 & 6 & 105 & GA02 & & & & & & & & & & & & nil & Yes \\
\hline \multirow{2}{*}{ Frencken $[28]$} & \multirow{2}{*}{ JDR } & 2006 & 85 & 622 & GA07 & 18 & 52 & 3 & 10 & 33 & 20 & 0.10 & $\begin{array}{c}0.03 \\
- \\
0.30 \\
\end{array}$ & $<0.00001^{*}$ & 0.20 & \begin{tabular}{|c|}
0.06 \\
- \\
0.66 \\
\end{tabular} & $0.008 *$ & No \\
\hline & & 2000 & 85 & $6 \angle 2$ & GA10 & 127 & 288 & 8 & 105 & 218 & 110 & 0.06 & $\begin{array}{c}0.03 \\
- \\
0.11 \\
\end{array}$ & $<0.00001^{*}$ & 1.12 & \begin{tabular}{|c|}
0.38 \\
- \\
3.34 \\
\end{tabular} & 0.83 & Yes \\
\hline $\begin{array}{c}\text { Estupiñán-Day } \\
{[29]}\end{array}$ & PAHO-report/Panama & 2006 & & & GA17 & 144 & 769 & 22 & 118 & 677 & 126 & 0.15 & $\begin{array}{c}0.10 \\
- \\
0.24\end{array}$ & $<0.00001 *$ & 2.46 & \begin{tabular}{|c|}
1.10 \\
- \\
5.48 \\
\end{tabular} & $0.03 * *$ & Yes \\
\hline
\end{tabular}

LTF = Number of restorations lost to follow-up; Vol. = Journal volume; DS = Dataset number; $\mathrm{N}=\mathrm{Number}$ of restorations evaluated; BSL = Number of restorations at baseline; $\mathrm{n}=$ Number of failed restorations; $\mathrm{RR}=$ Risk ratio; $\mathrm{CI}=$ Confidence interval; EurJProsthodontRestDent $=\mathrm{European}$ Journal of Prosthodontic Dentistry; JADA = Journal of the American Dental Association; PractClinMed = Practice Clinical Medicine; JDR = Journal of Dental Research; PAHO = Pan-American Health Organisation; *Difference statistically significant in favour of test group; ** Difference statistically significant in favour of control group.

As the number of accepted datasets was $<10$, no statistical and graphical assessment of publication bias risk was conducted. The search results from international and regional clinical trial registers and presented congress abstracts (Additional file S2/Section 8) identified six further studies that were presented from $2005-2013$ at dental congresses. Of these, five studies appeared to remain unpublished to date; while one study was only partially published in the format of a case report in a regional dental magazine [32]. All six studies appeared to be of split-mouth study design and thus would not have met the inclusion criteria of this review (Additional file S3).

\section{Extracted Data and Analysis}

From the six accepted clinical trials, 21 datasets were extracted. In addition, the review authors computed three further datasets from the information given in one trial report (Additional file S2/Section 3 and 4) [2]. No datasets for direct comparison between HVGIC and resin composite restorations in line with the set review inclusion criteria were identified.

Of the total 24 datasets nine datasets from three trials comparing composite resin versus amalgam restorations could be matched with nine datasets from three trials comparing HVGIC versus amalgam restorations, according to the minimum set of characteristics for clinical/methodological homogeneity: outcome measure; control intervention; cavity type restored; assessment method and length of follow-up period (Table 3). Each of the nine pairs was investigated for statistical inbetween-datasets heterogeneity $\left(I^{2}>40 \%\right.$; Cochrane's Q-test $/ p<0.10)$. Accordingly, five pairs were excluded and four pairs accepted for ITC (Table 4). All four pairs of accepted datasets appeared to be statistically homogeneous ( $I^{2}$ range: 0 - 39\%; Cochrane's Q-test $/ p$ value range: $0.20-0.96)$ and comprised:

Table 3. Datasets matching according to cavity class and follow-up period.

\begin{tabular}{|c|c|c|c|c|c|c|c|}
\hline \multirow{2}{*}{ Datasets } & \multirow{2}{*}{ Cavity class } & \multirow{2}{*}{ Follow Up (Mo) } & \multicolumn{5}{|c|}{ Statistical in-between datasets heterogeneity } \\
\hline & & & (Q) p-value & $I^{2}$ (in \%) & LCL & UCL & SHET \\
\hline CA01 versus GA02 & 2 & 24 & 0.95 & \begin{tabular}{|l|}
0 \\
\end{tabular} & \begin{tabular}{|l|}
0 \\
\end{tabular} & \begin{tabular}{l|l}
0 \\
\end{tabular} & No \\
\hline CA01 versus GA10 & 2 & 24 & 0.2 & 0 & 0 & 0 & No \\
\hline CA02 versus GA07 & 1 & 60 & 0.65 & 0 & 0 & 0 & No \\
\hline CA04 versus GA16 & $1+2$ & 24 & 0.12 & 59 & 0 & 90 & Yes \\
\hline CA04 versus GA17 & $1+2$ & 24 & 0.96 & 0 & 0 & 0 & No \\
\hline CA04 versus GA18 & $1+2$ & 24 & 0.02 & 82 & 22 & 96 & Yes \\
\hline
\end{tabular}


(Table प) contd......

\begin{tabular}{|c|c|c|c|c|c|c|c|}
\hline \multirow{2}{*}{ Datasets } & \multirow{2}{*}{ Cavity class } & \multirow{2}{*}{ Follow Up (Mo) } & \multicolumn{5}{|c|}{ Statistical in-between datasets heterogeneity } \\
\hline & & & (Q) p-value & $I^{2}$ (in \%) & LCL & UCL & SHET \\
\hline CA04 versus GA04+10 & $1+2$ & 24 & $<0.0001$ & 95 & 86 & 98 & Yes \\
\hline CA05 versus GA06+12 & $1+2$ & 48 & $<0.0001$ & 95 & 87 & 98 & Yes \\
\hline CA06 versus GA08 & $1+2$ & 72 & 0.07 & 69 & 0 & 93 & Yes \\
\hline
\end{tabular}

LCL = Lower 95\% Confidence level; UCL = Upper 95\% Confidence level; Mo = Months; sHET = Observed statistical heterogeneity.

i. Two pairs of datasets, CA01/GA02 [27, 31] and CA01/GA10 [28, 31], regarding tooth restorations placed in Class II cavities, after follow-up period of 24 months;

ii. One pair of datasets, CA02/GA07 [28, 30], regarding tooth restorations placed in Class I cavities, after follow-up period of 60 months;

iii. One pair of datasets, CA04/GA17 [2, 29], regarding tooth restorations placed in Class I/II cavities, after follow-up period of 24 months.

The characteristics of the datasets in the four pairs are listed in Additional file S2/Section 7. The type of information presented in the trial report about trial characteristics varied greatly and thus made further indepth comparison within each dataset pair impossible. However, from the comparison tables it can be discerned that patients within the dataset pairs CA01/GA02 $[27,31]$ and CA01/GA10 [28, 31] differed in age, while all other dataset pairs indicated similar age groups (Additional file S2/Section 7). No meta-analysis was conducted, due to lack of sufficient homogeneous data.
Assessment of all accepted datasets concerning the minimum sample size needed in order to have $>80 \%$ power for detecting an effect size difference of $10 \%$ between directly compared interventions showed that the sample size of the datasets included in the two ITCs concerning Class II restorations after 24 months were too small. However, the sample sizes in all datasets for the ITCs concerning Class I restorations after 60 months and Class I/II restorations after 24 months appeared sufficient (Additional file S2/Section 6).

The results of the ITC analysis are presented in Table 4. For the two ITCs concerning Class II restorations after 24 months, which involve zero cell counts, a fixed count of 0.5 was added to all cells of the treatment-by-outcome contingency table to avoid division by zero in the calculation of the Odds ratio.

The results of all four ITCs show no statistically significant difference between the failure rate of loadbearing HVGIC and resin composite restorations when placed in posterior permanent teeth, after 24 and 60month follow-up.

Table 4. Indirect treatment comparison (ITC) results.

\begin{tabular}{|c|c|c|c|c|c|c|c|}
\hline \multicolumn{8}{|c|}{ 1. Single dataset results } \\
\hline First author & Journal & Year & Vol. & First page & DS & OR & $95 \% \mathrm{CI}$ \\
\hline \multicolumn{8}{|c|}{ (a) Composite resin versus amalgam restorations } \\
\hline Sachdeo [31] & EurJProsthodont RestDent & 2004 & 12 & 15 & CA01 & 1.39 & $0.027-72.5$ \\
\hline Soncini [30] & JADA & 2007 & 138 & 763 & CA02 & 1.95 & $1.26-3.01$ \\
\hline Bernado [2] & JADA & 2007 & 138 & 775 & CA04 & 2.47 & $1.42-4.31$ \\
\hline \multicolumn{8}{|c|}{ (b) HVGIC versus amalgam restorations } \\
\hline Li [27] & PractClinMed & 2005 & 6 & 105 & GA02 & 1.52 & $0.80-2.90$ \\
\hline \multirow{2}{*}{ Frencken $[28]$} & \multirow{2}{*}{ JDR } & \multirow{2}{*}{2006} & \multirow{2}{*}{85} & \multirow{2}{*}{622} & GA07 & 1.13 & $0.36-3.55$ \\
\hline & & & & & GA10 & 0.13 & $0.03-0.53$ \\
\hline Estupiñán-Day [29] & PAHO-report/Ecuador & 2006 & & & GA17 & 2.51 & $1.11-5.69$ \\
\hline \multicolumn{8}{|c|}{ 2. ITC results: HVGIC versus composite resin restorations } \\
\hline DS-1 & DS-2 & OR & \multicolumn{5}{|c|}{$95 \% \mathrm{CI}$} \\
\hline CA01 & GA02 & 1.09 & \multicolumn{5}{|c|}{$0.02-59.90$} \\
\hline CA01 & GA10 & 0.09 & \multicolumn{5}{|c|}{$0.001-6.08$} \\
\hline CA02 & GA07 & 0.58 & \multicolumn{5}{|c|}{$0.17-1.97$} \\
\hline CA04 & GA17 & 1.02 & \multicolumn{5}{|c|}{$0.38-2.73$} \\
\hline
\end{tabular}

DS = Dataset number; Vol. = Journal volume; DS-1 = Dataset/Composite resin versus amalgam; DS-2 = Dataset/HVGIC versus amalgam; OR = Odds ratio; $\mathrm{CI}=$ Confidence interval; $\mathrm{ln}=$ Natural logarithm; $\mathrm{SE}=$ Standard error; EurJProsthodontRestDent $=$ European Journal of Prosthodontic and Restorative Dentistry; JADA = Journal of the American Dental Association; PractClinMed = Practical Clinical Medicine (journal); JDR = Journal of Dental Research; PAHO = Pan-American Health Organisation; HVGIC = High-viscosity glass-ionomer cement. 


\section{DISCUSSION}

\section{Limitations of The Systematic Review Method}

The aim of this systematic review was to answer the question as to whether conventional high-viscosity glassionomer restorations, in patients with single and/or multi-surface cavities in posterior permanent teeth, have indeed a higher failure rate than direct hybrid resin composite restorations. Despite the applied systematic literature search, no trials directly comparing HVGIC versus resin composite restorations could be identified that complied with the adopted set of inclusion/exclusion criteria. No search of Chinese and Latin American databases was included in this review and this may have contributed artificially to the observed paucity of suitable trials. However, it has been suggested that exclusion of non-English trial reports has little effect on the overall conclusions of systematic reviews [33, 34] and this appeared to have been confirmed by the results of a further systematic review by the authors to the topic of HVGIC versus amalgam tooth restorations [10]. For that reason, and although the omission of searching Chinese and Latin American databases may have limited the conclusion of this systematic review in principle, this limitation is assumed to have had no significant influence on the presented review conclusions.

Notwithstanding the lack of trials directly comparing HVGIC versus resin composite restorations, several trials comparing HVGIC versus amalgam and resin composite versus amalgam restorations could be identified. This allowed adjusted indirect comparison of the failure rates between HVGIC and composite resin, using the accepted ITC method by Bucher et al. (1997) [21]. However, the application of adjusted indirect comparison, as opposed to direct comparison of competing clinical interventions through RCTs, may have limited the precision of the presented results by generating wider confidence intervals [16]. Accordingly, adjusted indirect comparison results are less likely to be statistically significant $(p>0.05)$ than results from direct comparisons in RCTs. However, adjusted indirect comparison partially preserves the rigor of RCTs by considering the direct comparisons of both treatments of interest with the same controls [16]. Therefore, adjusted indirect comparison does not share the severe limitations of naïve-indirect comparisons.

One further potential limitation of indirect comparisons is related to the high risks of heterogeneity between trial characteristics of the compared groups. Although, in this systematic review great care was taken to only admit datasets for comparison that showed small risk of statistical heterogeneity (Table 3) and were sufficiently homogeneous in terms of outcome measure; control intervention; cavity type restored; assessment method and length of follow-up period, it was not possible to eliminate the risks of heterogeneity between the available datasets, completely.

\section{Systematic Literature Search}

The number of excluded studies, particularly for resin composite versus amalgam, was high (Additional file S2/Section 1). Most trial reports could not be accepted because they investigated older generations of restorative materials, such as chemically curing composite or low copper amalgam, that differed from those in current use and would have introduced further levels of clinical in-between-trial heterogeneity to the latter accepted RCTs.

Care was further taken not to include trials with splitmouth study design. Thus three trials comparing HVGIC versus amalgam restorations were excluded (Additional file S2/Section 1). Characteristics, such as higher risk for cavities and poorer oral hygiene and dietary behaviour in patients with at least two cavities, as opposed to patients with only one cavity in trials with parallel-group design, would have introduced clinical in-between-trial heterogeneity that needed to be avoided during ITC analysis. Such rather strict approach in trial selection according to aspects of lowest bias risk and highest achievable precision was needed, owing to the paucity of direct comparison/RCT in the current literature and in order to derive the most reliable and valid results through the more problematic adjusted indirect comparison method, instead.

Two trials investigating direct comparison of HVGIC versus resin composite restorations were identified through the systematic literature search [17, 32]. However, both trials were excluded. The trial by Diem et al. (2013) included composite restorations with HVGIC base, only, that would have introduced clinical HVGIC characteristics into the composite treatment group [17]. The trial by Gurgan et al. (2013) was only partially reported in a dental magazine at search cut-off date and, thus was unsuitable for further review [32].

\section{Assessment of Internal Trial Validity/Bias Risk}

All of the accepted trials appear limited by risk of either selection- and/or detection-/performance bias.

Only two trials reported on the use of an adequate randomisation method [29, 30]. Nonetheless, all trials failed to report not only on evidence of successful sequence allocation and allocation concealment results, but also on necessary details about how sequence allocation and allocation concealment were attempted (Table 1) [12]. None of the trials, therefore, provide any 
guarantee that each patient had an equal chance of being allocated to either treatment group.

From the onset, in all trials successful blinding or masking appeared not to have been possible, owing to the obvious differences in clinical appearance between the compared materials. For that reason, the allocation to either treatment group was visible to patients and operators. Only two trials reported adequate methods of masking/blinding of the trial evaluators [28, 30]. However, no evidence was reported as to whether such methods were indeed successful. Against this background, the danger of detection-/performance bias may have affected the trial results. Potential knowledge of superiority claims prior to the trial may thus have led evaluators to apply different rigor in their assessments of the different treatment groups.

On the basis of the results of the quantitative risk assessment (Table 2), the risk for attrition bias may be regarded as high in all compared datasets, but particularly for the comparison of Class I tooth restorations after a 60-month period (DS CA02 versus GA07) [28, 30].

Owing to the low number of available datasets $(N<$ 10) it was not possible to establish information concerning publication bias risk through graphical and statistical methods. However, the lack of listed trial protocols and relevant conference abstracts of unpublished trials suggests that the risk of publication bias to the reviewed topic may be low.

\section{Statistical Analysis of Results}

Based on the conducted ITC analysis, the 95\% Confidence intervals of all four Odds ratios (ORs) included 1.00, thus indicating no statistically significant difference between HVGIC and resin composite restorations (Table 4). The relatively large width of the confidence intervals may confirm previous observations [35] that adjusted indirect comparison gives lower precision than direct comparisons. Such lower precision may thus also be prevalent for ITC results for which a sufficiently high sample size in datasets was established (Additional file S2/Section 6).

\section{Recommendations for Further Research}

The available evidence suggests no difference in the failure rates between both types restoration beyond the play of chance, is limited by lack of head-to-head comparisons, an insufficient number of trials, as well as by high bias and in-between-dataset heterogeneity risk. Therefore the current evidence requires corroboration by large-sized, parallel-group, randomised control trials that compare HVGIC with resin composite restorations. Such future trials should avoid attrition bias risk through high loss-to-follow-up; include an investigation of performance/detection bias influence into its methodology, and test for selection bias risk, using the Berger-Exner test in order to quantitatively ascertain the level of adherence to the allocated random sequence throughout the trial [12].

\section{CONCLUSION}

Superiority claims regarding the failure rates of direct hybrid resin composite restorations above that of conventional high-viscosity glass-ionomer restorations, in patients with single and/or multi-surface cavities in posterior permanent teeth, cannot be justified by the current poor clinical evidence to this topic. Direct headto-head comparisons through clinical sufficiently largesized parallel group randomised control trials with high internal validity are needed in order to justify any clinically meaningful judgement.

\section{CONFLICT OF INTEREST}

One of the authors (SM) has been actively involved in the promotion; teaching and research of GIC tooth restorations in the past (from 1998 - 2007).

\section{ACKNOWLEDGEMENTS}

The authors thank Dr Petra Gaylard for her assistance during statistical analysis and Mrs. Joy Hull for editing the grammar and syntax of the manuscript of this report.

\section{SUPPLEMENTARY MATERIAL}

Supplementary material is available on the publisher's web site along with the published article.

\section{Additional File S1}

Systematic literature search / Internal validity criteria.

\section{Additional File S2}

References, extracted data and information from accepted trials.

\section{Additional File S3}

Congress abstracts.

\section{REFERENCES}

[1] Rekow ED, Fox CH, Petersen PE, Watson T. Innovations in materials for direct restorations: why do we need innovations? Why is it so hard to capitalize on them? J Dent Res 2013; 92(11): 945-7.

[http://dx.doi.org/10.1177/0022034513507058] [PMID: 24130248] 
[2] Bernardo M, Luis H, Martin MD, et al. Survival and reasons for failure of amalgam versus composite posterior restorations placed in a randomized clinical trial. J Am Dent Assoc 2007; 138(6): 775-83

[http://dx.doi.org/10.14219/jada.archive.2007.0265] [PMID: 17545266]

[3] Antony K, Hiebinger C, Genser D, et al. Haltbarkeit von Zahnamalgam im Vergleich zu Kompositkunststoffen (Article in German). GMS Health Tech Assess 2008; 4: Doc12. [PMID: 21289917]

[4] Downer MC, Azli NA, Bedi R, Moles DR, Setchell DJ. How long do routine dental restorations last? A systematic review. Br Dent J 1999; 187(8): 432-9.

[http://dx.doi.org/10.1038/sj.bdj.4800298a1]

[PMID: 10716002]

[5] Hickel R, Manhart J, García-Godoy F. Clinical results and new developments of direct posterior restorations. Am J Dent 2000; 13(Spec No): 41D-54D.

[PMID: 11763918]

[6] Hickel R, Manhart J. Longevity of restorations in posterior teeth and reasons for failure. J Adhes Dent 2001; 3(1): 45-64. [PMID: 11317384]

[7] Manhart J, Chen H, Hamm G, Hickel R. Buonocore Memorial Lecture. Review of the clinical survival of direct and indirect restorations in posterior teeth of the permanent dentition. Oper Dent 2004; 29(5): 481-508.

[PMID: 15470871]

[8] Frencken JE, Van 't Hof MA, Van Amerongen WE, Holmgren CJ. Effectiveness of single-surface ART restorations in the permanent dentition: a meta-analysis. J Dent Res 2004; 83(2): 120-3.

[http://dx.doi.org/10.1177/154405910408300207] [PMID: 14742648]

[9] Wang X, Nie J, Cai X, et al. Failure rate of atraumatic restorative treatment using high-viscosity glass-ionomer cement compared to conventional amalgam restorative treatment in primary and permanent teeth: a systematic review of Chinese trials. J Minim Interv Dent 2012; 5: 377-415.

[10] Mickenautsch S, Yengopal V. Failure rate of high-viscosity GIC based ART compared with that of conventional amalgam restorations--evidence from an update of a systematic review. SADJ 2012; 67(7): 329-31.

[PMID: 23951787]

[11] Mickenautsch S, Yengopal V. Failure rate of direct tooth restorations placed with conventional glass-ionomers compared to composite resin restorations in posterior permanent teeth: a systematic review and network metaanalysis [protocol]. J Minimum Interv Dent 2013; 6: 62-72.

[12] Berger VW. Selection bias and covariate imbalances in randomised clinical trials. Chichester, UK: John Wiley \& Sons, Ltd 2005.

[http://dx.doi.org/10.1002/0470863641]

[13] Taifour D, Frencken JE, Beiruti N, van't Hof MA, Truin GJ, van Palenstein Helderman WH. Comparison between restorations in the permanent dentition produced by hand and rotary instrumentation--survival after 3 years. Community Dent Oral Epidemiol 2003; 31(2): 122-8. [http://dx.doi.org/10.1034/j.1600-0528.2003.00027.x] [PMID: 12641593]

[14] Higgins JPT, Green S. Cochrane Handbook for Systematic Reviews of Interventions Version 5.1.0 [updated March 2011]: Section 9.5.2. The Cochrane Collaboration 2011. Available from: www.cochrane-handbook.org, [Accessed: 10 ${ }^{\text {th }}$ Nov 2013].

[15] Ioannidis JP, Patsopoulos NA, Evangelou E. Uncertainty in heterogeneity estimates in meta-analyses. BMJ 2007; 335(7626): 914-6.

[http://dx.doi.org/10.1136/bmj.39343.408449.80] [PMID: 17974687]
[16] Glenny AM, Altman DG, Song F, et al. International Stroke Trial Collaborative Group. Indirect comparisons of competing interventions. Health Technol Assess 2005; 9(26): 1. [http://dx.doi.org/10.3310/hta9260] [PMID: 16014203]

[17] Diem VT, Tyas MJ, Ngo HC, Phuong LH, Khanh ND. The effect of a nano-filled resin coating on the 3-year clinical performance of a conventional high-viscosity glass-ionomer cement. Clin Oral Investig 2014; 18(3): 753-9.

[http://dx.doi.org/10.1007/s00784-013-1026-z]

[PMID: 23832616]

[18] Song F. What is indirect comparison? UK: Hayward Medical Communications 2009. Available from: http://www.whatis series.co.uk/whatis/pdfs/What_is_ind_comp.pdf, [Accessed: $10^{\text {th }}$ Nov 2013].

[19] Jansen JP, Fleurence R, Devine B, et al. Interpreting indirect treatment comparisons and network meta-analysis for healthcare decision making: report of the ISPOR Task Force on Indirect Treatment Comparisons Good Research Practices: part 1. Value Health 2011; 14(4): 417-28.

[http://dx.doi.org/10.1016/j.jval.2011.04.002]

[PMID: 21669366]

[20] Hoaglin DC, Hawkins N, Jansen JP, et al. Conducting indirecttreatment-comparison and network-meta-analysis studies: report of the ISPOR Task Force on Indirect Treatment Comparisons Good Research Practices: part 2. Value Health 2011; 14(4): 429-37.

[http://dx.doi.org/10.1016/j.jval.2011.01.011]

[PMID: 21669367]

[21] Bucher HC, Guyatt GH, Griffith LE, Walter SD. The results of direct and indirect treatment comparisons in meta-analysis of randomized controlled trials. J Clin Epidemiol 1997; 50(6): 683-91.

[http://dx.doi.org/10.1016/S0895-4356(97)00049-8] [PMID: 9250266]

[22] Vandermeer BW, Buscemi N, Liang Y, Witmans M. Comparison of meta-analytic results of indirect, direct, and combined comparisons of drugs for chronic insomnia in adults: a case study. Med Care 2007; 45(10) (Suppl. 2): S166-72. [http://dx.doi.org/10.1097/MLR.0b013e3180546867] [PMID: 17909377]

[23] Wells GA, Sultan SA, Chen L, et al. Indirect treatment comparison [computer program]. Version 1.0. Ottawa: Canadian Agency for Drugs and Technologies in Health 2009.

[24] Roulet JF, Mettler P, Friedrich U. A clinical comparison of three composites with amalgam for class II fillings under special consideration of the curettage. Results after 2 years. Schwe Monats Zahnh 1980; 90: 18-30.

[25] Hoyer I, Gängler P, Niemela S. Composite and amalgam fillings in a 4-year clinical comparison. Zahn Mund Kieferheilkd Zentralbl 1988; 76(7): 721-6. [PMID: 2975115]

[26] Banday N, Dogon L, Saeed F. A clinical trial using glass ionomers amalgams and composites (part II). J Pak Dent Assoc 2002; 11: 137-41.

[27] Li H-M, Dou Z-H. Clinical observation of using different material in the elderly decaying tooth ART technique (Article in Chinese). Pract Clin Med 2005; 6: 105-7.

[28] Frencken JE, Taifour D, van 't Hof MA. Survival of ART and amalgam restorations in permanent teeth of children after 6.3 years. J Dent Res 2006; 85(7): 622-6.

[http://dx.doi.org/10.1177/154405910608500708] [PMID: 16798862]

[29] Estupiñán-Day S, Milner T, Tellez M. Oral health of low income children: procedures for atraumatic restorative treatment (PRAT) - Final report. PAHO Project number 091024: ATN/JF-7025-RG. 2006. 
[30] Soncini JA, Maserejian NN, Trachtenberg F, Tavares M, Hayes C. The longevity of amalgam versus compomer/composite restorations in posterior primary and permanent teeth: findings From the New England Children's Amalgam Trial. J Am Dent Assoc 2007; 138(6): 763-72. [http://dx.doi.org/10.14219/jada.archive.2007.0264] [PMID: 17545265]

[31] Sachdeo A, Gray GB, Sulieman MA, Jagger DC. Comparison of wear and clinical performance between amalgam, composite and open sandwich restorations: 2-year results. Eur J Prosthodont Restor Dent 2004; 12(1): 15-20. [PMID: 15058177]

[32] Gurgan S, Firat E, Kutuk ZB. Two-year study on the clinical performance of the glass ionomer based restorative system EQUIA. J Minimum Interv Dent 2013; 6: 81-6.
[33] Jüni P, Holenstein F, Sterne J, Bartlett C, Egger M. Direction and impact of language bias in meta-analyses of controlled trials: empirical study. Int J Epidemiol 2002; 31(1): 115-23. [http://dx.doi.org/10.1093/ije/31.1.115] [PMID: 11914306]

[34] Moher D, Pham B, Klassen TP, et al. What contributions do languages other than English make on the results of metaanalyses? J Clin Epidemiol 2000; 53(9): 964-72.

[http://dx.doi.org/10.1016/S0895-4356(00)00188-8] [PMID: 11004423 ]

[35] Song F, Harvey I, Lilford R. Adjusted indirect comparison may be less biased than direct comparison for evaluating new pharmaceutical interventions. J Clin Epidemiol 2008; 61(5): 455-63.

[http://dx.doi.org/10.1016/j.jclinepi.2007.06.006] 18394538]

\begin{tabular}{ll}
\hline Received: March 1, 2015 & Revised: October 15, 2015
\end{tabular}

Accepted: October 16, 2015

(C) Mickenautsch and Yengopal; Licensee Bentham Open.

This is an open access article licensed under the terms of the (https://creativecommons.org/licenses/by/4.0/legalcode), which permits unrestricted, noncommercial use, distribution and reproduction in any medium, provided the work is properly cited. 